\title{
Utilization of coal sludge as reductant in the direct reduction of
}

\author{
titanomagnetite ore \\ Chao Geng ${ }^{1, a)}$; Tichang Sun ${ }^{1)}$; Huifeng Yang ${ }^{1)}$ \\ ${ }^{1}$ China School of Civil and Environmental Engineering, University of Science and Technology \\ Beijing, Beijing 100083, China \\ agengchao1988@yeah.net
}

Keywords: coal sludge; direct reduction; titanomagnetite; desulfurization

Abstract: Coal-based direct reduction followed by magnetic separation was used to produce direct reduction iron powder (DRIP) from a titanomagnetite (TTM) ore. The residual solid wastes which are called coal sludge in this paper are still discarded as waste in large quantities. To explore the feasibility of using coal sludge as reductant, two types of coal sludge, namely, TJ and SX, with different dosages were investigated. Results showed that this process can realize coal-sludge utilization, and good DRIP products were obtained. The suitable dosage of coal sludge depended on the fixed carbon content of coal sludge. TJ and SX presented a similar result in reducing the TTM ore, i.e., TTM ore was reduced to iron, ilmenite, and ferrous pseudobrookite by both TJ and SX; improved Fe recovery in DRIP was further achieved by increasing the dosages of the two coal sludge, but the increased dosage was unfavorable to $\mathrm{Fe}$ grade and $\mathrm{TiO}_{2}$ content. The sulfur contained in coal sludge occurred in the form of troilite in the reduced ore. Because troilite is a nonmagnetic material, it was removed into tailings after magnetic separation. Thus, the process presented a good ability of desulfurization.

\section{Introduction}

Coal sludge, one of the by-products of coal preparation, consists of coal, dirt, and clay; it is characterized by high moisture, high content of ash and S, low calorific value, and fine particles $(-74 \mu \mathrm{m}>70 \%)$ [1]. Currently, apart from coal sludge with high calorific value and low $\mathrm{S}$ content that are used for fluidized-bed boiler to generate power, most coal sludge have not been effectively utilized. More than 1 million tons of coal sludge are produced by coal preparation plants in China every year[2]. The same situation has also occurred in other countries. But the residual solid wastes which are called coal sludge in this paper are still discarded as waste in large quantities. Large areas of land are needed to store these coal sludge, which reduces the area of usable farming land. The construction and maintenance of coal sludge disposal sites also increase the production cost of coal preparation plants. Even more problematic, coal sludge contain high content of chemical reagents after flotation process, the release of chemical reagents, such as alkaline oxides, from these storage sites could cause serious environmental pollution in soil and water[3,4]. Therefore, the treatment and disposal of coal sludge is becoming an urgent problem on a global scale.

Recently, a significant attention has been devoted to research the production of direct reduction iron powder (DRIP) from titanomagnetite (TTM) ore by coal-based direct reduction followed by magnetic separation[5-8]. In this process, the TTM ore mixed with reductant and additives is reduced to metallic iron and titanium minerals, and then the reduced ore are ground and separated by magnetic separation to produce DRIP. The DRIP product obtained with this process generally 
contains more than 90 mass\% Fe and is used as a substitute for steel scrap in electric arc furnaces (EAF) for steelmaking[9]. Generally, coke, anthracite, graphite, or bitumite was used as reductant to produce DRIP in the researches, which leads to high cost. Good DRIP products (Fe grade $>90 \%, \mathrm{Fe}$ recovery $>85 \%$, and $\mathrm{TiO}_{2}$ content $<1 \%$ ) were obtained with these reductants. Coal sludge has similar characteristics as coal. Therefore, coal sludge may be used as reductant instead of coal. However, the $S$ content of coal sludge is relatively higher than that of other coal types. The sulfur content of the feed stock for steelmaking must be strictly controlled. According to research[10], the process of coal-based direct reduction followed by magnetic separation presents a good desulfurization because a physical separation technique is involved in this process. Therefore, this process may become a novel approach to utilize coal sludge.

In the present work, a TTM ore was reduced with two coal sludge as reductant through direct reduction followed by magnetic separation process, and the feasibility of using coal sludge as reductant was investigated.

\section{Experimental}

\section{Material}

The TTM ore used was obtained from Indonesia. It assays 51.85 mass $\% \mathrm{Fe}, 11.33$ mass $\% \mathrm{TiO}_{2}$, 14.43 mass \% $\mathrm{SiO}_{2}, 6.86$ mass\% $\mathrm{Al}_{2} \mathrm{O}_{3}, 3.64$ mass\% $\mathrm{MgO}$, and 1.09 mass\% $\mathrm{CaO}$. Two types of coal sludge, namely, TJ and SX, produced by different coal preparation plants, were used as reductants in this paper. The proximate analysis results of the two coal sludge are shown in Table 1. The components of the two coal sludge are extremely different. The ash and S content of TJ are lower than that of SX, and the fixed carbon of TJ is higher than that of SX. Both coal sludge have low calorific value.

Table1. The proximate analysis content of coal sludge

\begin{tabular}{|c|c|c|c|c|c|c|}
\hline \multirow{2}{*}{ Coal sludge code } & \multicolumn{4}{|c|}{ Air-dried basis ad/[mass \%] } & \multicolumn{2}{c|}{$\begin{array}{c}\text { Calorific value/ } \\
{[\mathrm{MJ} / \mathrm{kg}]}\end{array}$} \\
\cline { 2 - 7 } & Ash & Volatiles & Fixed carbon & Sulfur content & Gross & Net \\
\hline TJ & 29.31 & 26.37 & 42.90 & 0.57 & 21.74 & 18.56 \\
\hline SX & 44.55 & 23.92 & 29.50 & 0.95 & 16.03 & 13.25 \\
\hline
\end{tabular}

The size of TTM ore in the experiments were less than $1 \mathrm{~mm}$ and the coal sludge was 90 mass \%, passing $0.074 \mathrm{~mm}$.

\section{Experimental Procedure}

The TTM ore ( $20 \mathrm{~g})$ was thoroughly mixed with additives and coal sludge (the dosage of coal sludge varied from 15 to 30 mass $\%$ ). The mixture was placed in a graphite crucible. The crucible was then placed into a muffle furnace chamber at $1250{ }^{\circ} \mathrm{C}$ and then withdrawn after $60 \mathrm{~min}$. The reduced ore was cooled to room temperature and ground in a rod mill. The slurry was separated in a CXG-99 Davies Magnetic Tube. The methods of grinding and magnetic separation have been described elsewhere[11,12].

The magnetic product obtained referred to the DRIP. The Fe grade, Fe recovery, and $\mathrm{TiO}_{2}$ and $S$ content in the DRIP were used to determine the feasibility of using coal sludge as reductant. The Fe recovery referred to the percentage of the total iron metal contained in the ore that was recovered in the DRIP. 


\section{Results and Discussion}

\section{Reduction and Separation Results}
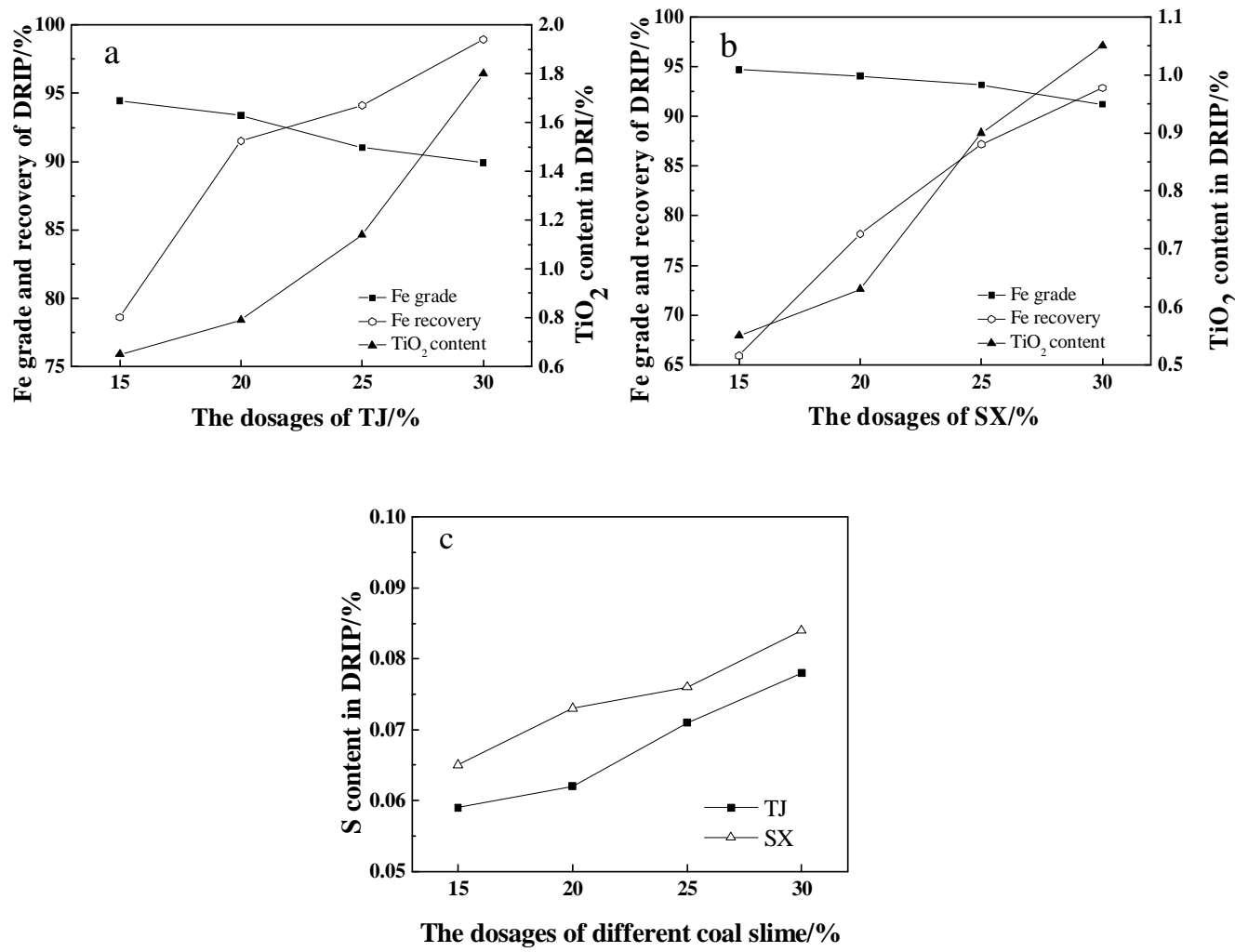

Fig.1. Effects of coal sludge and dosages on the DRIP

The effect of dosages of different coal sludge on the reduction of TTM ore was studied, and the variation curves are presented in Fig. 1. As shown in Fig. 1(a), increasing the dosage of TJ from $15 \%$ to $30 \%$ causes a sharp increase on both the Fe recovery and $\mathrm{TiO}_{2}$ content; the $\mathrm{Fe}$ recovery increases from $78.59 \%$ to $98.95 \%$, and the $\mathrm{TiO}_{2}$ content increases from $0.65 \%$ to $1.8 \%$. However, the Fe grade decreases from $94.44 \%$ to $89.92 \%$ with the increased dosage of TJ from $15 \%$ to $30 \%$. The experiment data illustrate that a suitable dosage is beneficial to the separation of titanium and iron. Excessive dosage increases Fe recovery, but it is disadvantageous to the $\mathrm{TiO}_{2}$ content and Fe grade of DRIP. Therefore, the suitable dosage of TJ is $20 \%$. As shown in Fig. 1(b), the changing trend of the experiment data obtained by SX is similar with that of TJ. The Fe recovery increases from $65.92 \%$ to $92.85 \%$, the $\mathrm{TiO}_{2}$ content increases from $0.55 \%$ to $1.05 \%$, and the Fe grade decreases from $94.68 \%$ to $91.21 \%$ with the increased dosage of SX from $15 \%$ to $30 \%$. The suitable dosage of SX is approximately $25 \%$, which is higher than that of TJ. When the TJ and SX dosages are at the suitable dosages of $20 \%$ and $25 \%$, the Fe grade of DRIP are $93.38 \%$ and $93.16 \%$, the Fe recovery of DRIP are $91.51 \%$ and $87.18 \%$, and the $\mathrm{TiO}_{2}$ content in DRIP are $0.79 \%$ and $0.90 \%$, respectively. The experimental data of DRIP obtained in this work are similar with the reported data in previous studies that used coal as reductant[6,8], which proves that coal sludge (i.e., TJ and SX) can be used as reductant instead of coal. As shown in Fig. 1(c), the S content increases with the increasing dosages of TJ and SX, but the S content in DRIP obtained by the two coal sludge were both less than 0.1 mass $\%$. The $\mathrm{S}$ content of the DRIP has been strictly controlled and met the requirements of $\mathrm{S}$ content in EAF, which indicates that the process presents a good ability of desulfurization. 


\section{XRD Analysis}

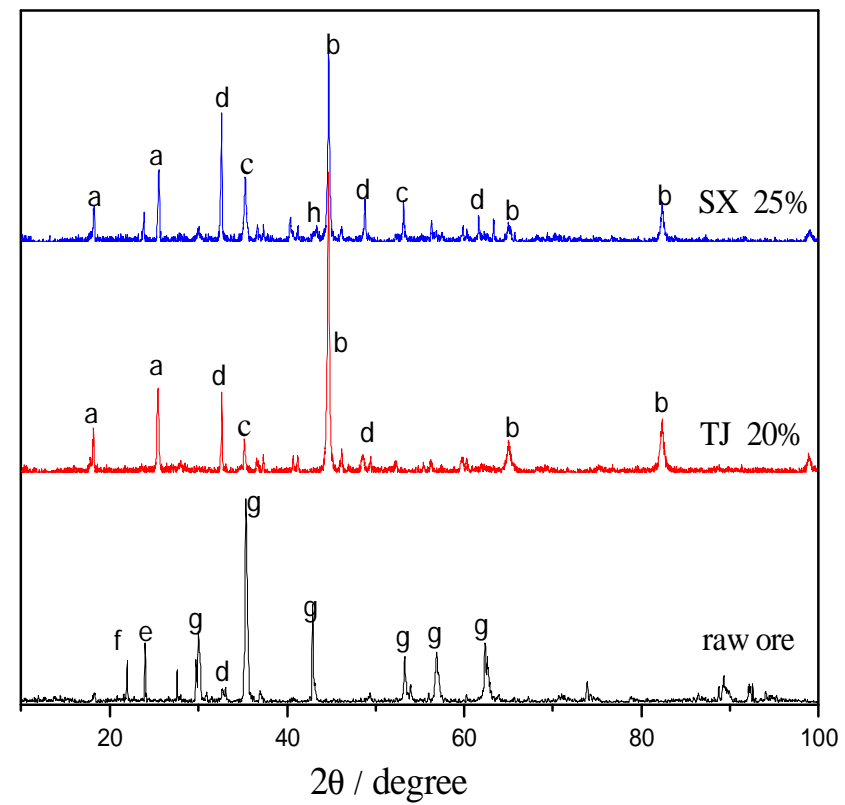

Fig. 2. XRD patterns of roasted ores obtained at the suitable dosages of $T J$ and $S X$ a-ferrous pseudobrookite $\left(\mathrm{FeTi}_{2} \mathrm{O}_{5}\right)$, b-iron $(\mathrm{Fe})$, c-ulvospinel $\left(\mathrm{Fe}_{2} \mathrm{TiO}_{4}\right)$, d-ilmenite $\left(\mathrm{FeTiO}_{3}\right)$, e-nepheline $\left(\mathrm{Na}_{2} \mathrm{Si}_{2} \mathrm{O}_{5}\right)$, f-quartz $\left(\mathrm{SiO}_{2}\right)$, g-titanomagnetite $\left(\mathrm{Fe}_{2.75} \mathrm{Ti}_{0.25} \mathrm{O}_{4}\right)$, h-troilite $(\mathrm{FeS})$

$\mathrm{X}$-ray diffraction (XRD) patterns were used to study the effects of coal sludges on the phase transitions in the TTM ore. The mineralogical phase transformations of iron and titanium minerals caused by coal sludges are presented in Fig. 2.

The raw ore consisted of TTM (g), ilmenite (d), and quartz (f). When TJ is used as the reductant in the reduced ore at the suitable dosage of 20\%, the diffraction peak of TTM disappears; the main phases are iron (b), ferrous pseudobrookite (a), ilmenite (d) and ulvospinel (c). When SX is used as a reductant at the suitable dosage of $25 \%$, the phase transitions are similar with that of TJ. The results illustrate that the TTM ore can be reduced by TJ and SX, respectively.

When the dosage of SX is $25 \%$, the peak of troilite (h) was observed, and it explains that the $\mathrm{S}$ contained in coal sludge occurred in the form of troilite (FeS) in the reduced ore. To fully verify the experimental data, the reduced ore obtained with different dosages of different coal sludges were studied by scanning electron microscope (SEM).

\section{SEM Observation}

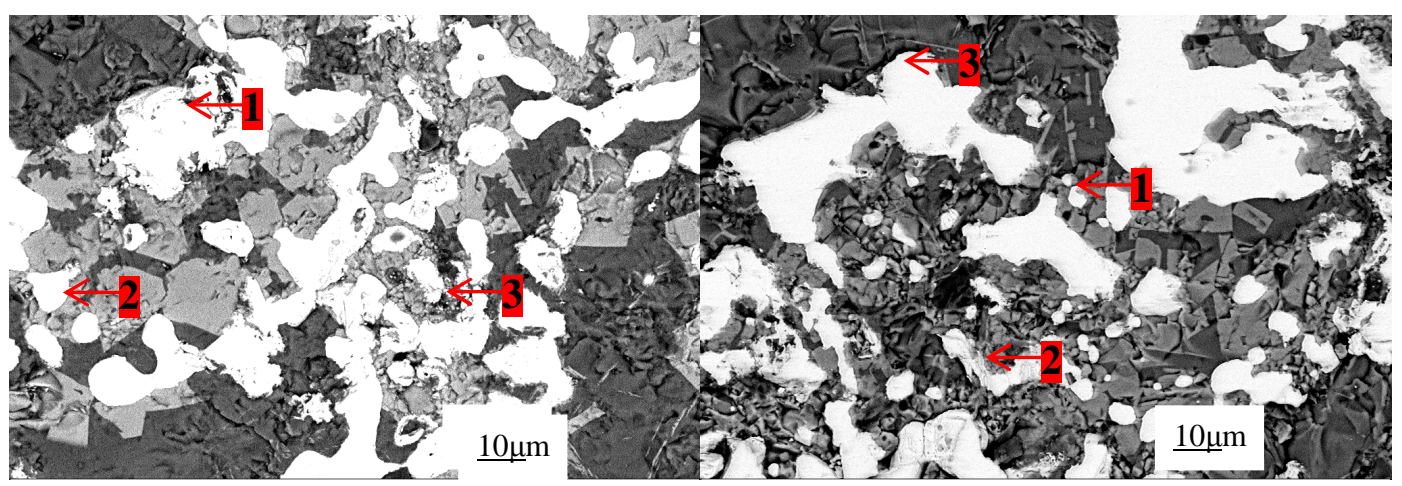

(a) SEM image of 20 mass $\%$

(b) SEM image of 25 mass $\%$ SX 

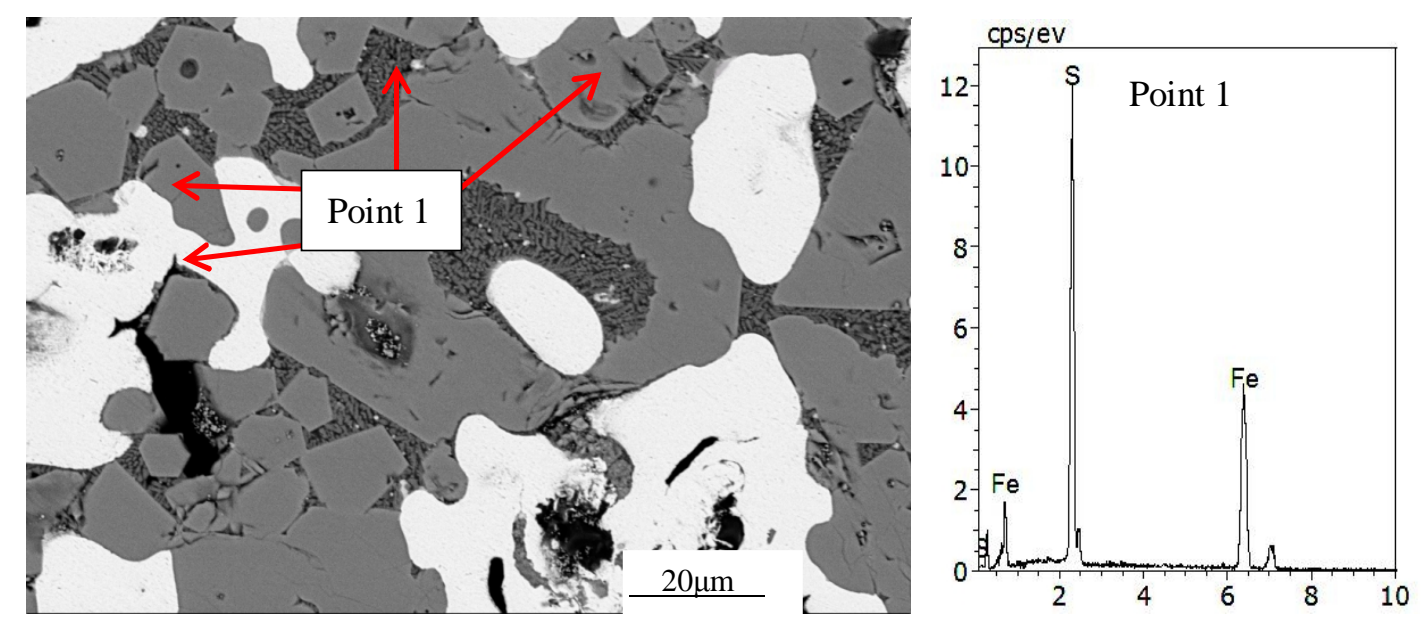

(c) Distribution of sulfur in the reduced ore with 25 mass\% SX

Fig. 3. SEM images and EDS results of reduced ores

1-iron; 2-titanium minerals; 3-silicate minerals

The SEM images of the reduced ore with the suitable dosage of 20 mass $\%$ TJ and 25 mass\% SX were showed in fig.3 (a) and fig.3 (b). The bright phase (spot 1), gray phase (spot 2), and the black areas (spot 3) observed by the energy dispersive spectrometry (EDS) analysis are iron, titanium minerals, and silicate minerals, respectively.

Fig.3 (a) and (b) show that the microstructures of the reduced ore with suitable dosage of $20 \%$ TJ and $25 \% \mathrm{SX}$ are similar, the reduced ore surface is saponaceous, the particle size of most iron particles exceeds $30 \mu \mathrm{m}$, there is an obvious boundary between the iron particles and titanium minerals. This boundary is beneficial to the separation of the metallic iron particles and non-magnetic titanium minerals through grinding-magnetic separation. The evidence obtained thus far supports that the coal sludge used as reductant could reduce the TTM ore and get good DRIP products.

The distribution of sulfur in the reduced ore with 25\% SX was observed by SEM with EDS in fig.3 (c). Fig.3 (c) shows that most of FeS grains enclose metallic iron and a few of them are located in between two iron particles. Through grinding, these FeS particles enclosed iron particles can be liberated from metallic iron. FeS is a nonmagnetic material that falls from the tailing after magnetic separation. However, a few of FeS located in the middle of two iron particles were difficult to remove completely. Therefore, the DRIP with low S content was obtained. Moreover, the effective desulfurization of this process further proved that coal sludge with high $\mathrm{S}$ content such as $\mathrm{SX}$ can be used as reductant.

\section{Conclusions}

To develop the applications of coal sludge, the reduction of TTM ore to obtain DRIP products with two types of coal sludge was examined.

(1) According to the experimental results with different coal sludges, good DRIP products were obtained by the two coal sludges. TJ and SX presented a similar result in reducing the TTM ore. During the dosages of the two coal sludges, the suitable dosages of TJ and SX were 20 mass\% and 25 mass\%, respectively.

(2) Based on the XRD and SEM analyses, the TTM ore was reduced to iron, ilmenite, and ferrous pseudobrookite by the two coal sludges, respectively. Under the suitable dosages, iron particles were big enough, the boundary between the iron particles and titanium minerals was obvious, which was beneficial to the separation. 
(3) The S contained in the coal sludges occurred in the form of FeS in the reduced ore. As a nonmagnetic material, FeS was removed from the DRIP after the magnetic separation, and the DRIP with low content of S was obtained.

\section{Acknowledgements}

The authors wish to express their thanks to the Natural Science Foundation of China (No.51474018) for the finance support for this research.

\section{References}

[1] Q. He, D. Xie, R. Xu, T: Fuel, Vol. 159 (2015), p. 40.

[2] X. Tao, Y. Cao, J. Liu, K. Shi, J. Liu and M. Fan: Procedia Earth and Planet. Sci, Vol. 01(2009), p. 799.

[3] L. Zhao, L. Wang, T. Qi, D. Chen, H. Zhao and Y. Liu: Hydrometallurgy, Vol. 149(2014), p.106.

[4] N. El-Hazek, T. A. Lasheen, R. El-Sheikh and A. Zaki: Hydrometallurgy, Vol.87(2007), p.45.

[5] H. Sun, X. Dong, X. She, Q. Xue and J. Wang: ISIJ Int., vol. 53(2013), p. 564.

[6] E. X. Gao, T. C. Sun, C. Y. Xu, Z. G. Liu and C. X. Yu: Metal Mine, Vol. 38 (2013), p. 46.

[7] T. Hu, X. Lv, C. Bai, Z. Lun, and G. Qiu, Metall. Mater. Trans. B, Vol. 44B(2013), p. 253.

[8] B. H. Gao, H. J. Wang, Y. Qu and L. Li: Min. Metal. Eng., Vol. 32(2012), p. 44.

[9] W. Yu, T. Sun, Q. Cui, C. Xu and J. Kou: ISIJ Int., Vol. 55(2015), p.536.

[10] W. Yu, T. Sun, and T. Hu: ISIJ Int., Vol. 55(2015), p. 329.

[11] C. Geng, T. Sun, H. Yang, Y. Ma, E. Gao and C.: ISIJ Int., Vol. 55(2015), pp. 2543.

[12] C. Yu, T. Sun, C. Xu and E. Gao: Min. Metal. Eng., Vol. 34(2014), pp. 93. 